\title{
The Wills Eye Manual Office and Emergency Room Diagnosis and Treatment of Eye Disease Fifth Edition Eds: Justis P. Ehlers and Chirag P. Shah 2008 455pp., Softcover US\$79.95, £39.00 ISBN: 978-0-7817-6962-4 Lippincott Williams \& Wilkins
}

\author{
Michael Ulbig \\ Received: 1 October 2008 / Accepted: 6 October 2008 /Published online: 4 November 2008 \\ (C) Springer-Verlag 2008
}

Keywords Ophthalmology $\cdot$ Residents $\cdot$ Retina

This handbook is a classic for all residents and for those experiencing their first night in the ophthalmological emergency room. The book is very useful. The compact format allows it to be in the surgeon's pocket, albeit a white coat with large pockets!

The title "Wills Eye Manual" tells it all (written by members of the Wills Eye Hospital), and although it is rather a short manual it does advise how to act immediately. The first modern edition was published in 1990, and by now generations of residents have "grown" with it. It is simple where it should be simple (paperback), and has high quality where needed with glossy paper inside and lots of colour photographs.

There are 455 pages in total, and more than 200 clinical illustrations. This leaves little room for the senior staff member to show his superior skills beyond the content of this handbook. Each disease is presented with coloured headlines such as symptoms, signs, differential diagnosis, work-up, treatment, and follow-up, and there are over 200 ophthalmic entities reviewed. Thus, the book is comprehensive enough to cover the most important diseases and casualties of the eye in a busy outpatient clinic. On the other hand, references are not incorporated in order to keep

\section{Ulbig ( $\square)$}

Department of Ophthalmology, University of Munich,

Mathilden Strasse 8,

80336 Munich, Germany

e-mail: Michael.Ulbig@med.uni-muenchen.de the book concise. The index is well-sorted, and all abbreviations are explained at the end of the book. The overall layout and structure is helpful in order to reach diagnoses as quickly as possible and to find the best treatment.

For instance, it is possible to look for signs such as cotton wool spots or cystic macular oedema which lead to the most important differential diagnoses. The book is wellwritten, and the language is easy to understand even for ophthalmologists whose native tongue is not English. Text blocks are as short as possible, which is helpful in gaining an overview at a glance.

The overall content is correct and up-to-date. Even modern tools of treatment such as anti-VEGF therapy for CNV have been included in this fifth edition. More oldfashioned treatments such as PDT are mentioned in combination with intravitreal triamcinolone and as an alternative. Thus, the resident can be left alone with this book and the patient. Imaging modalities have their own chapter, and it is explained what they can be used for in ophthalmology. This includes also computer tomography and MRT, not only typically ophthalmological investigations.

The book really addresses all ophthalmologists who are on duty in the emergency room or on call, but it remains useful later on in private practice too. There are few chances to miss the proper diagnosis with this book in hand, or at least on the shelf. The success of the Wills Eye Manual will continue with this new edition. This classic is now up to date again and incorporates the latest advances in ophthalmology. The book absolutely accomplishes the aims of the authors. In the present form, the Wills Eye Manual is again very competitive in its field. 